\title{
Case Study \\ Entrepreneurs Test the Market: Got (Goat's) Milk Soap?
}

\author{
Laurence M. Weinstein \\ Kelli Bodrato*
}

\section{The Four-Year Itch?}

Sitting around the kitchen table one late-winter morning, Lisa and Rick Agee were discussing which direction to take their small, home-based business located in rural New Milford, Connecticut, over the next three to five years. The couple was making and selling "Goatboy" brand bathroom soap using goat's milk as the key ingredient, and they were now trying to reconcile very different points of view on how to grow the business in early March 2006.

Although unit business volume had increased from 10,000 units in 2003 to 40,000 units in 2005, the Agees still had not yet reached a point where they were generating enough profit to sustain the business well into the future; it seemed the two of them were so bogged down in the day-to-day operation of the company that they were not yet confident their venture would be successful. Funds were running out and both Lisa and Rick were quietly getting desperate about what they should do next.

Lisa was saying over breakfast to her husband, Rick, and a friend who was visiting, "I am tired, just bone tired, of making and packaging our soap bars by hand. It takes me almost 20 hours a week just to do my part to get the product ready to ship. It would be a far better use of my time to put together a formal business plan and get out of the house more often to market the brand to huge potential buyers like the Stop \& Shop chain. [Stop \& Shop is a large, regional supermarket chain in Northeastern United States.]

"I want to go to gift shows in New York and Boston where there's tremendous excitement and sales action. It's a waste of time for me to be selling one and two bars of soap at a time to customers who come to our home or for me to attend country fairs. We need to advertise and grow this business much faster than we have so far. I want badly for our company to be the next Burt's Bees" (Burtsbees.com 2006). ${ }^{1}$

Rick retorted, "Frankly, I don't see the need for a business plan and I don't think we should go anywhere near the Stop \& Shop chain. Tell you why. Growth has been doubling every year since our first full year of business in 2003 and that's just with word-of-mouth promotion and some nice publicity pieces in local newspapers. Why change the way we operate? Besides, it's dangerous to grow too fast. I love going to the local area farmers' markets and to the summer fairs because I enjoy meeting new people who learn about our products

*Coauthor of teaching notes and then tell us how much they love them. Plus, building our business on the Internet is a fun challenge."

Lisa responded, "Rick, fun is not the operative word here. Surviving would be more like it."

\section{The Original Concept}

For the Agees, starting up their business came from a very real family need and, for them, "necessity was absolutely the mother of invention." The concept that led to their in-home business was indirectly caused by a very sick infant. Lisa Agee said, "My second child had significant allergies when he was born. At three days old, he would double over in pain when I tried to feed him milk. I knew something was terribly wrong and that I had to do something fast."

"The answer, after a lot of hasty research on the Internet and discussions with my pediatrician, was to feed him goat's milk." Their son thrived and his nickname became "Goatboy" because he depended upon, and drank, large quantities of goat's milk. And that also is why the Agees came to choose "Goatboy" as the name for their business.

\section{From Milk to Soap}

The insights about the values of goat's milk led eventually to introducing their children to goats at a nearby farm some years later and, for Lisa, a notion that perhaps goat's milk products could be a lot better for human consumption and for her family's health than cow's milk. Lisa was personally motivated to look into alternative products because each winter she would "scratch herself raw" as her skin was dried out from using regular soaps, even Dove brand bars, that claimed to contain creams which would soften and moisturize the skin.

"What a scam that is," offered Lisa. "The soap companies take out the glycerin that is produced during the soap-making process and sell the glycerin to other manufacturers who want the by-product for their own brands and uses. That leaves bar soaps with harsh detergents getting consumers' skin 'squeaky clean' but requiring lotions to remoisturize their bodies when what we really need, adults especially, is something that will be cleansing but not so harsh on the skin."

These perceptions led Lisa to an Internet site in 2001 where she was able to locate a woman in upstate New York 
offering soap made from goat's milk. Having previously had very positive experiences with goat's milk for her son, Lisa immediately ordered several bars of the product and was pleased with its performance. Using only the goat milk soap product, Lisa's skin healed after two months and she has never returned to using regular commercial bar soaps.

\section{The Product}

Impressed with the potential of goat milk products, Lisa and Rick started to make their own goat milk soap later in 2001, and within months they found a ready market among other families interested in using the product. By 2003, both Lisa and Rick decided to leave corporate life and concentrate on the manufacturing and marketing of their soap. The business had been incorporated in late 2002 as a limited liability company to give the Agees certain tax and debt protection advantages (for a fuller discussion, go to http://sbinformation.about.com/cs/ownership1/a/LLC.htm 2006). In their rural area, the Agees were allowed both to own goats on their property and manufacture the soap. Their herd consisted of six Nubian goats, with three of the four females pregnant and due to deliver their kids by June 2006.

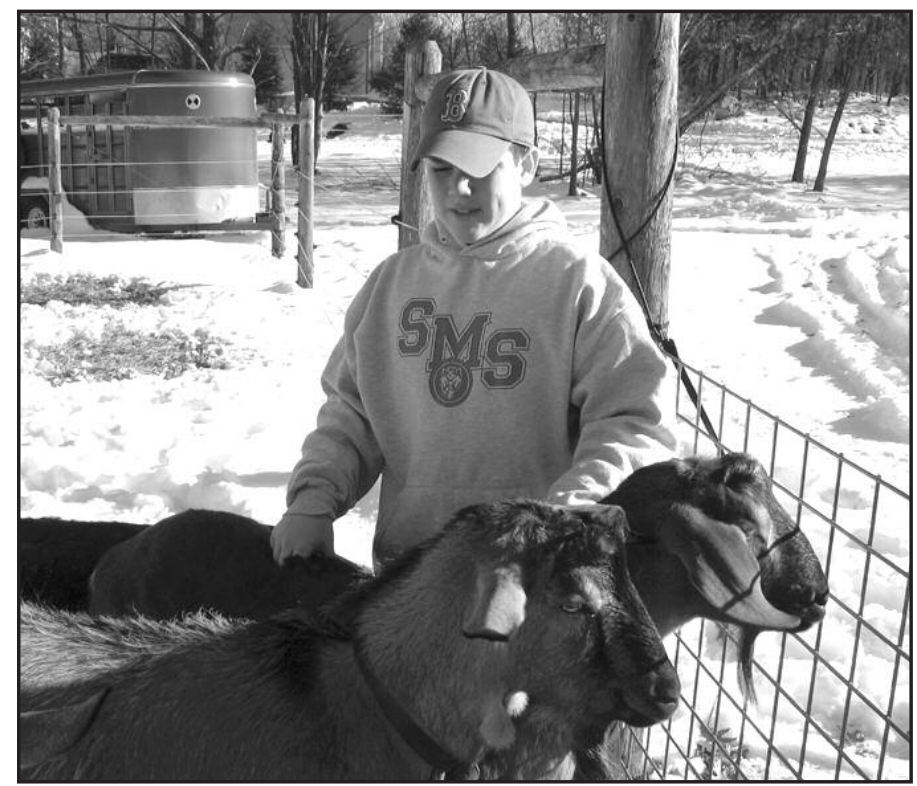

Bobby Agee tends to the family's Nubian goats.

Initial capitalization of the company came from taking out a mortgage of $\$ 100,000$ on their home in New Milford. Family inheritance had enabled the Agees to buy their $\$ 300,000$ home without any debt. Now, they were tapping into their home equity to cover the costs of buying manufacturing equipment, purchasing initial ingredients, paying for initial sleeve packaging and other materials, plus paying their personal bills and a mortgage payment of roughly $\$ 6,000$ per month while they waited for the business to start generating income.
The Agees also had to learn how to make bathroom soap. They used various sources including a local chemist, several Internet sites, and some local library textbooks. Rick, who is very handy, said, "The process itself wasn't hard to learn, but you have to be careful to mix the ingredients properly and take care not to hurt yourself around the lye and the high heat needed to make bar soap."

The product was made by heating goat's milk with Shea butter, along with olive, palm, and coconut oils in 55-gallon metal drums to $100^{\circ} \mathrm{F}$. Lye was then added; reacting to the fat in the goat milk, the solution heated up dramatically and had to be pneumatically stirred to avoid burning. When the mixture reached the correct "trace" thickness, the liquid was poured into molds where it was left to cool for the next 48 hours. Next, the soap product was cut into logs where it cured for the following 30 days. Finally, the logs were cut into individual bars and packaged by hand.As of January 2006, the Agees could produce up to 1,200 bars daily.

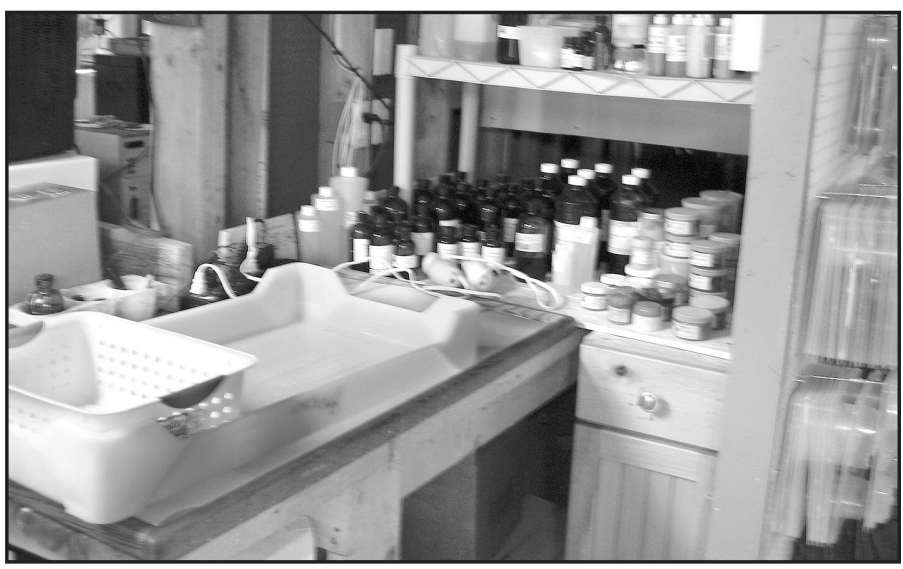

Small batches of product are manufactured using natural ingredients goat's milk, saponified oils, and fragrance.

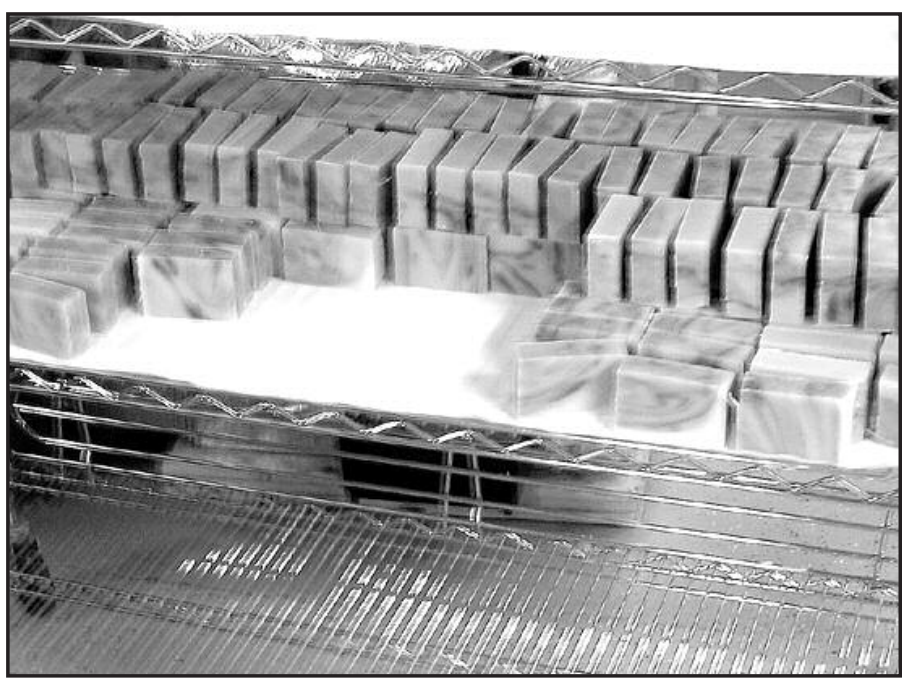

Goatboy soap cures for 30 days before being cut into individual bars and packaged by hand. 
The Agees also made lip balm and skin lotion from goat's milk using manufacturing processes similar to their bar soap, but these product line additions accounted for less than $\$ 15,000$ of their total gross income in 2005 .

\section{Target Audience}

The Agees had come to the conclusion from talking to hundreds of prospective buyers at county fairs and farmers' markets that their audience consisted primarily of female headof-households, aged 30-60, with moderate or better family incomes, both rural and suburban home-owners, who all suffered from dry and/or sensitive skin. "While women are primarily the purchasers," said Lisa, "I suspect the majority of our users are men, 30+. Surprising, isn't it? Get this: We offer a wide variety of fragrances, such as blackberry sage, herbal French clay, almond, lavender, red clover tea, lilac, serious citrus, and oatmeal. Men really have taken to the different scents and they appreciate how mild the soap is on their skin. Men come up to our summer fair or farmers' market booth all the time and tell me how much they love our soap products!"

Although it appeared counterintuitive that men would be heavy users, Lisa insisted her insight into the marketplace was accurate despite the lack of any formal market research to confirm her feelings. She based her beliefs solely on the informal sampling of men who approached the family-run booth and discussed the soap with the Agees.

\section{Sales}

At the end of 2005, Lisa and Rick roughly estimated their sales revenue came from five different sources, in these percentages (see also Figure 1):

- farmers' markets, 35 percent

- retail accounts, 15 percent

- summer fairs, 20 percent

- Internet, 15 percent

- home parties, 15 percent

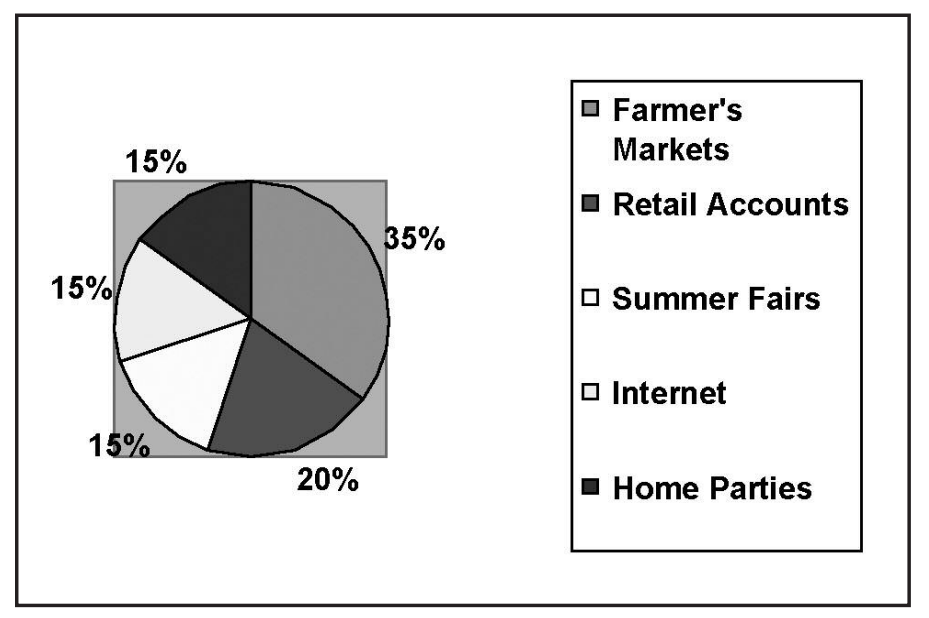

Figure 1. Sales Revenue by Source

\section{Price}

Each 4.5-ounce bar of Goatboy Soap was priced at $\$ 5.00$ retail; when purchased directly from the Agees, consumers were able to buy three bars for $\$ 10$, or $\$ 3.33$ each-a savings of 33 percent. However, even with this price reduction, anyone who used the soap had to have a real appreciation for the benefits of the goat milk product because store-bought bar soap retailed for far less than what the Agees were charging for their product (see Table 1).Although the goat milk bar lasted twice as long as comparable commercial bar soap, according to the Agees, the product was still more expensive to use than nationally branded soap because of the larger price differential. Lisa was quick to point out, though, there were additional savings for her customers in not having to buy moisturizing creams so often, or not at all, which made her product line no more expensive than competitive soap brands from Dial, Procter \& Gamble, and Unilever if one added the cost of the body cream to the initial purchase of store-bought bar soap.

\begin{tabular}{|l|l|l|}
\hline \multicolumn{3}{|c|}{ Table 1. Price Comparisons by Brand } \\
\hline Soap Brand & Size & Unit Price \\
\hline Dial & $4.5 \mathrm{oz}$. & $\$ 0.11 / \mathrm{oz}$. \\
\hline Dove & $4.25 \mathrm{oz}$. & $\$ 0.32 / \mathrm{oz}$. \\
\hline Goatboy & $\mathbf{4 . 5} \mathrm{oz}$. & $\$ \mathbf{0 . 7 4} / \mathrm{oz}$. \\
\hline Ivory & $4.5 \mathrm{oz}$. & $\$ 0.13 / \mathrm{oz}$. \\
\hline Lever 2000 & $4.5 \mathrm{oz}$. & $\$ 0.27 / \mathrm{oz}$. \\
\hline Olay & $4.75 \mathrm{oz}$. & $\$ 0.34 / \mathrm{oz}$. \\
\hline Goatboy price calculated at $\$ 3.33 / \mathrm{bar})$ \\
\hline
\end{tabular}

\section{Profit Margins}

Profit margin was 70 percent when the product was sold directly to the end-user at $\$ 5.00$ per bar, based on a cost to manufacture of $\$ 1.50$. Price to distributors or direct-buying retailers was in the $\$ 3-\$ 3.50$ per unit range, depending on volume, establishing margins for the Agees of at least 50 percent. Retailers who purchased the product, at say, \$3.00 and resold each bar for $\$ 5.00$, made a 67 percent markup and a 40 percent margin. Those robust markup and margin percentages were a strong incentive for carrying the line as commercial bar soaps frequently provided markups of only 10 to 15 percent in comparison. ${ }^{2}$

Whole Foods, headquartered in Greenwich, Connecticut, a regional natural foods supermarket, authorized their store managers to accept the product line into their Northeast stores in September 2005 (Wholefoods.com 2006). The Agees were scrambling to visit every store during late 2005 and early 2006 to convince each local store manager to accept an initial stocking order of a gross of soap (144 units). Through March 2006, six Whole Foods locations in New York and Connecticut had made the commitment to

Entrepreneurs Test the Market: Got (GoAt's) Milk Soap? 21 
stock Goatboy soaps, generating initial sales of nearly 1,000 units, and the Agees upgraded their packaging to increase their shelf presence.

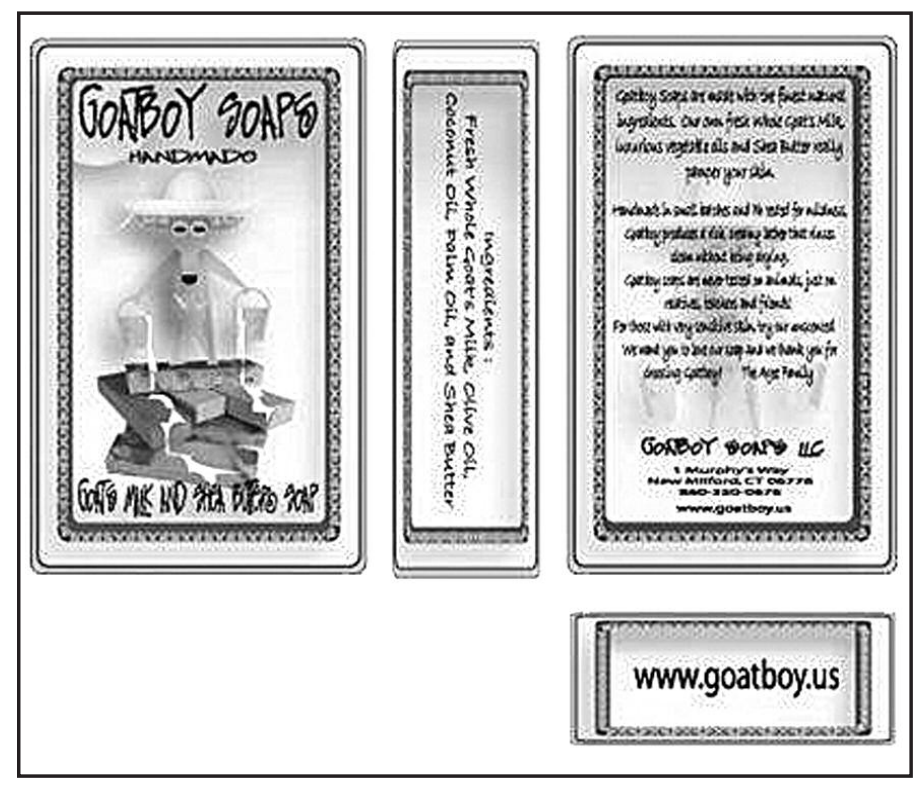

Goatboy Soap packaging.

\section{Promotion}

As of spring 2006, Lisa and Rick had not advertised nor used sales promotion behind their soap, lip balm, and skin lotion product lines in mass media outlets such as newspapers or radio. Their business budget did not allow for paid advertising although they recognized the fact that at some point it would definitely help their sales if they were to start promoting Goatboy more aggressively. The Agees did try bartering their products for airtime in early 2005 over radio station, "I95," in the Hartford, Connecticut, area, but after several months decided not to continue their association with the radio station. Product awareness was helped to some degree because several of their customers mentioned hearing the on-air mentions of their product. However, the Agees felt that this effort had led to very few actual incremental sales and was not worth the cost of supplying the station with free samples.

The primary vehicle for creating awareness of their company occurred whenever Lisa and Rick attended farmers' markets and local town fairs in Connecticut and Massachusetts from May to September.They also regularly mailed samples of their product line to any prospective supermarket retailers, health food stores, bed \& breakfast owners, and talk-show personalities who approached them or who the Agees thought might be interested in the product.

Occasionally, the Agees had been interviewed by local newspaper reporters and their business had received very positive publicity. One example of this coverage occurred in July 2005 when the Seymour, Connecticut, first selectman (the town's mayor) decided to ban the Agees from bringing their goats to the town's fair because a local resident had complained the goats were a public nuisance. When word spread about the ban, the local town residents became angry; they protested and barraged the first selectman with emails until he relented.The associated newspaper and cable television coverage out of New Haven and Hartford, Connecticut, greatly helped raise the awareness level, and interest in, the company's products (Benton 2005).

Rick said, "After that experience, we were hoping that every mayor and first selectman would follow suit and ban our goats. The attention we received, and the support we got from the community, was overwhelming. You can't buy that sort of stuff."

The company also maintained and regularly updated an Internet site at www.goatboy.us, which told the story of the company, displayed the product line, discussed the benefits of using goat milk soap, and showed how to order the product online (Goatboy.us 2005).

The Agees' latest publicity breakthrough came when they were videotaped by producers of the CBS network program, "Market Watch," in December 2005 (the show aired in February 2006). Although other entrepreneurs were shown during the 30-minute program, the Agees received more than 15 minutes of airtime and Goatboy brand soaps were the main feature of the program.

\section{Unit Sales}

As of spring 2006, unit sales had been increasing briskly. Figure 2 shows the sizeable increase in bar soap sales year to year, with a doubling of units sold each year since the first full year of product introduction in calendar year 2003.

Could the business continue to generate sales increases of 100 percent each year? The Agees certainly hoped so. Even at 80,000 units, the Agees would be operating at only one-third daily production capacity. This was a cause for concern because the initial expense of buying their equipment was quite high (more than \$20,000), and they were anxious to realize a return on their capital investment.

Rick had not yet conducted sophisticated financial analyses for the company, but the Agees had estimated that they would be able to earn up to $\$ 175,000$ in gross income if they both went back to corporate jobs. Subtracting taxes, social security and medical benefit deductions, their corporate incomes would have netted the Agees roughly \$120,000 annually, a comfortable sum with which to raise their family without the expense and effort of running a family business.

For the business to generate that same sum in profit from selling goat milk products, Rick assumed that each bar of soap sold generated at least a $\$ 1.50$ in gross margin. Additional expenses such as utility bills, transportation costs, business insurance, a new truck, veterinary charges, and 
taxes were at least another 95 cents per bar, leaving a net unit profit of 55 cents. Rick mused, "I sure do need to sell a lot of soap to make my nut of $\$ 120,000$."

Should they continue the business? The Agees were currently selling 80,000 bars per year with the business doubling from year to year.That would mean they could conceivably sell 160,000 bars of soap in 2007 . Could their money hold out? The original $\$ 100,000$ they borrowed against their home had nearly run out. They were discussing borrowing another \$100,000 from the equity in their house but this was a decision they were not yet ready to make because their mortgage expense would increase by at least $\$ 500$ per month in interest payments alone.

\section{Biggest Obstacle}

The biggest impediment to further growth, at least for now, was lack of product exposure and distribution, according to Lisa. One recent success was the decision by Guido's Supermarket, located in Great Barrington and Pittsfield, Massachusetts, to begin stocking their products. Although initial sales had been encouraging, the Agees still did not have sales representatives to make sure that stock depletion was avoided by constantly restocking the shelves every week. "Neither Rick nor I have the time to follow-up on Guido's and make sure we don't suffer from out-of-stocks. This makes me wonder if we're going to succeed with Guido's and with Whole Foods as well," she said. "Hiring a sales force to keep track of what's on the shelf at these supermarkets would be time-consuming and very expensive. We simply cannot consider it at the moment."

\section{Growing Internet Competition}

Interestingly, over the past two years (from 2004 to 2006), Lisa had noticed a marked increase in entrepreneurial activity in natural bar soaps. She was not sure why this phenomenon had occurred, but Lisa had noted that consumers across the country appeared to be leaning more and more toward cottage industry products that promised distinct benefits over mass-merchandized brands.

A particular worry for Lisa was that Goatboy Soaps might lose its differentiation from commercial bar soaps and, more importantly, from the other Internet-based soap companies such as Goatmilk Goodness, Utterly Delightful Goatmilk Soap, and Goat Milk Skin Care Soap, because consumers had such an overwhelming number of sources for the product. What made the Goatboy brand distinct? Was there a strong "reason why" consumers should buy their products from the Agees and not someone else? These thoughts were beginning to haunt Lisa and she did not know what to do about it.

\section{A "Champion" Would Help, but Is It a Fantasy?}

Lisa wished she had a "champion" for their product line. Some radio personalities, such as Don Imus in New York, were interested in helping small businesses and consistently talked up products like Bigelow Tea whose main office was nearby in Fairfield, Connecticut. If popular network television stars like Oprah Winfrey or Ellen Degeneres would only "discover" goat milk soap, it would put the Agees "on the map." However, getting the attention of these popular stars was extremely hard to do. Thousands of small businessowners like the Agees all sought that kind of attention. Lisa had sent baskets of product to both Oprah and Ellen but had heard nothing back from either celebrity. For all Lisa and Rick knew, someone on the staff had simply taken the baskets home and used the product without Oprah or Ellen ever being the wiser.

\section{Looking Ahead}

If the product line did not grow substantially by spring 2007 , one of the Agees would definitely have to seek employment in the corporate sector or else Rick and Lisa would have to

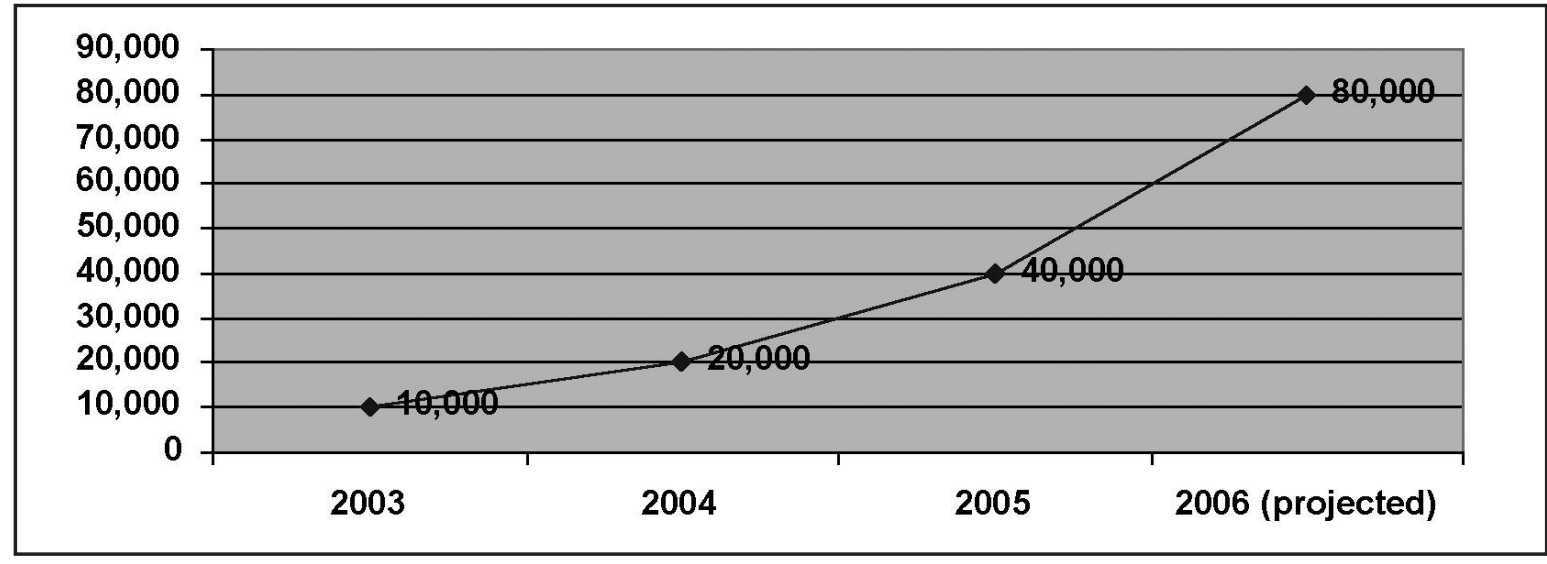

Figure 2. Unit Bar Soap Sales 2003-2006 (Projected)

(Rounded to nearest thousand; data supplied by the Agees) 
borrow once again from their home's equity line and/or seek an outside investor. Either option was not appealing to them; they wanted to make their venture a success and keep it within the family, but that all depended on achieving substantially more product awareness and distribution in the months-and years-ahead.

Lisa still wanted to put together a business plan and even a marketing plan eventually, but Rick's resistance to formal planning and her own ambivalence to formalizing aspects of their business meant that planning would continue to take a back seat. Whatever publicity they received in the months ahead would have to occur serendipitously.

Rick still believed the business could grow organically and slowly enough for the Agee family to maintain tight control over the purchasing, manufacturing, and sales functions. Rick believed that by attending enough summer farmers' markets and town fairs the business would eventually become big enough to sustain him and his wife indefinitely. Lisa, on the other hand, was becoming increasingly dissatisfied with having to take care of so many business details and keep their home open at all hours just to sell one or two bars of soap at a time. Lisa had bigger dreams and wanted to expand the business exponentially. She wanted to appear on the Oprah Winfrey Show and other national formats where the goat milk soap business would be exposed to substantially more consumers and where they stood a chance of being noticed by influential people. People who might one day make them as successful as Burt's Bees.

As the discussion ended, the doorbell rang. It was a customer who wanted to buy five bars of soap. Rick's eyes lit up; Lisa was less impressed. "Another \$20 or so. Big deal. At this rate, we'll be out of business soon," she commented. "Is there light at the end of this tunnel for us?"

Decisions needed to be made. Should the Agees follow Rick's desire to grow slowly and use an informal planning style with a day-to-day time horizon or would Lisa's more aggressive approach make more sense with faster growth and the use of a formal planning system? If they could not reconcile their different perspectives, the business, and possibly their marriage, might be at risk.

\section{Endnotes}

1. Founded in 1984, Burt's Bees produces personal care products made from beeswax, nut oils, and other natural ingredients sold worldwide in boutiques and health food stores. For more information, see www.burtsbees.com.

2. Whole Foods buyer in conversation with Rick Agee in 2005.

\section{References}

Burtsbees.com website. Retrieved February 27, 2006.

Benton, Elizabeth. 2005. Goat back at Valley Farmers' Market. New Haven Register, August 18.

Goatboy.us website. Retrieved December 19, 2005.

Wholefoods.com website. Retrieved January 11, 2006.

\section{About the Authors}

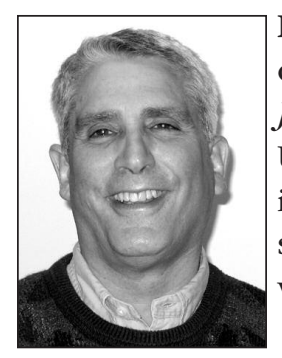

LAURENCE WEINSTEIN (weinsteinL@sacredheart.edu) is a professor of management in the John F. Welch College of Business at Sacred Heart University, Fairfield, Connecticut. He cofounded and edited the New England Journal of Entrepreneurship for eight years. He graduated with the Ed.D. and M.B.A. degrees from Columbia University. Prior to his joining academe full time in 1977 , Dr. Weinstein was a product manager for seven years in consumer packaged goods and then spent two years as a partner in a small business. His research and consulting interests include case studies on varied marketing topics, entrepreneurial start-ups, and small business ventures.

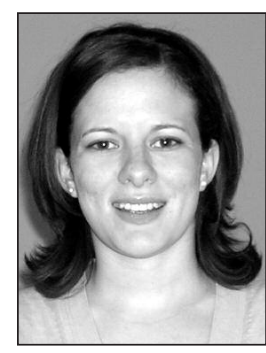

Kelli Bodrato (bodratok@sacredheart.edu) is a Masters in Business Administration candidate in the John F. Welch College of Business at Sacred Heart University. This is Ms. Bodrato's first published paper. She will begin her Ph.D. degree in higher education in the fall of 2007. 